\title{
Globe
}

Revue internationale d'études québécoises

\section{Intimité et culture}

\section{Daniel Chartier}

Volume 3, numéro 1, 2000

L'intime et le privé au Québec

URI : https://id.erudit.org/iderudit/1000562ar

DOI : https://doi.org/10.7202/1000562ar

Aller au sommaire du numéro

Éditeur(s)

Globe, Revue internationale d'études québécoises

ISSN

1481-5869 (imprimé)

1923-8231 (numérique)

Découvrir la revue

Citer ce document

Chartier, D. (2000). Intimité et culture. Globe, 3(1), 9-9.

https://doi.org/10.7202/1000562ar d'utilisation que vous pouvez consulter en ligne.

https://apropos.erudit.org/fr/usagers/politique-dutilisation/ 


\section{Présentation Intimité et culture}

Pour entreprendre sa troisième année, la revue publie un numéro culturel, avec un dossier thématique sur les questions de l'intime et du privé au Québec, réuni par Laurier Lacroix et Isabelle Thellen. Le thème est abordé par Pierre Rajotte dans la perspective de la pratique du récit de voyage au XIXe siècle, puis par Gilles Lapointe sous l'angle de la loi du secret dans la correspondance entre deux artistes du Refus global de 1948, soit le poète, dramaturge et polémiste Claude Gauvreau et le peintre automatiste Paul-Émile Borduas. Suivent l'article de Jeanette den Toonder, sur les voyages intérieurs dans trois romans récents de la littérature québécoise et celui de Julie Lavigne sur la voix féministe de l'intime chez l'artiste Geneviève Cadieux.

Le numéro se poursuit en études libres avec une réponse de l'ancien directeur du Devoir et ex-chef de l'opposition officielle à l'Assemblée nationale, Claude Ryan, à l'article de James Tully sur les sociétés multinationales, publié dans notre précédente livraison. Puis, Isabelle Décarie étudie l'idée de transnationalisme à travers L'Hiver de Mira Christophe, une cuvre du poète, romancier et essayiste Pierre Nepveu. Enfin, Jean-Pierre Boucher présente une analyse de l'œuvre méconnue d'Albert Laberge, un écrivain contestataire de la première moitié du vingtième siècle. Après les recensions, ce numéro se termine sur une nouvelle section sur les parutions récentes en études québécoises.

Daniel CHARTIER directeur GLOBE, Revue internationale d'études québécoises Chercheur associé Institut national de la recherche scientifique - Culture et Société 